\title{
ENTRE O UNIVERSALISMO E A CONDIÇÃO CONTEXTUAL: CONCEPÇÕES E LIMITES DO HUMANISMO SECULAR DE EDWARD SAID
}

Para o campo das ciências sociais, a relevância da obra de Edward Said pode ser situada em um entendimento original da relação entre as dimensões da política e da cultura, sobretudo no exame de modos pelos quais formas de identificação social e política se manifestam e se impõem, de um lado, e podem ser contestadas, de outro. Ainda que a cultura reflita um poder estruturado, é também um campo dinâmico que incorpora conflitos de significação através dos quais a ordem social se reproduz e é experimentada. Assim, o âmbito cultural não aparece como sistema fechado de significados, mas imerso em práticas de conflito que acabam por configurar a possibilidade de uma pluralidade de significações. Na medida em que as relações entre política e cultura são tomadas como instâncias não estáveis, observa-se tanto uma estrutura consistente quanto instabilidade política, o que pode ser melhor entendido a partir dos mecanismos de representação que refletem poder e, por vezes, processos de resistências. Tais mecanismos fundamentam-se em relações definidas entre saber e poder, tendo o conhecimento e os intelectuais papel fundamental em sua manutenção ou questionamento.

Um dos desafios centrais assumidos por Said é questionar verdades científicas e filosóficas, mostrando as regras que governam suas construções. Propõe uma crítica, então, a argumentações totalizantes e essencializadoras e busca, paralelamente, definir bases para uma reflexão comparativa e abrangente. Por um lado, o autor (Said, 2007b: 27-29) ressalta os problemas da su- 
posição da "soberania do sujeito" do humanismo tradicional, definida por uma filosofia do sujeito que circunscreve o pensamento em si mesmo, sem conexões com os contextos sociais delimitados pela própria ação dos homens. Nesse sentido, Said recupera aspectos da tradição teórica - sobretudo do estruturalismo e pós-estruturalismo, mas também, como assinala, de Marx, Kuhn e Freud, por exemplo - que aponta o necessário envolvimento da percepção em sistemas de pensamento, de modo a notar paradigmas e epistemes que dominam as áreas do conhecimento e impõem regras de formação de conceitos e da linguagem teórica. Por outro lado, Said questiona tendências de um anti-humanismo - como o refletido em teorias pós-modernas - que supõem a inviabilidade de grandes narrativas de crítica e emancipação, sugerindo, diferentemente, uma prática cognitiva voltada para a reconstrução de parâmetros universais.

Said (2007b) defende um novo humanismo que, baseado nas potencialidades da reflexividade e liberdade modernas, supere circunstâncias particulares em benefício de uma compreensão cosmopolita, já que seria "possível ser crítico ao humanismo em nome do humanismo" (Said, 2007b: 29) desde que estivéssemos atentos aos abusos da experiência do eurocentrismo e do imperialismo. Como demonstrado na expressão política de novas identidades sociais e na presença marcante de teorias feministas, étnicas, de novas sexualidades, assim como dos novos estudos culturais e pós-coloniais, não faria mais sentido a defesa de essencialismos, a exaltação de virtudes do passado ou a tese da intangibilidade de cânones. Portanto, questiona-se um humanismo centrado em postura apolítica e não mundana que se atém a ressaltar virtudes de uma grande tradição ou defender leis gerais e naturais, reivindicando, em seu lugar, outro humanismo com potencial racional de avaliar, comparar e revelar questões e fatos criados por forças sociais concretas. ${ }^{\mathrm{I}}$

O "humanismo secular" de Said articula-se com uma nova concepção analítica que busca ir além do provincianismo e de contraposições hierarquizadas. A proposta, neste ponto refletindo aspectos centrais da reflexão pós-colonialista, nega afirmações fixas e excludentes, enfatizando o papel das minorias e a fluidez de identidades que se opõem aos discursos hegemônicos, não mais capazes de representar a dinâmica complexa da contemporaneidade. Além disso, tal proposta contrapõe-se à antimodernidade do humanismo clássico, principalmente às exclusões elitistas que normalizam um tipo de identidade, selecionam regras, interpretações, autores e leitores privilegiados, além de reproduzirem uma imagem cognitiva pretensamente apolítica (Said, 2007b: 60). Said (I993: xiii; 2005: 40) expõe o humanismo que critica por meio das teses de Matthew Arnold, escritas ainda na segunda metade do século XIX, exemplares do desconforto de várias tendências teóricas em relação ao movimento de universalização de direitos, de urbanização e de mercantilização. O temor central daquelas reflexões seria a queda de padrões e cânones 
que serviam de referência de pensamento e conduta, sobretudo para a pequena elite que deveria reproduzi-los. Arnold referia-se, particularmente, às dificuldades de se governar a sociedade com a ascensão política das massas, tendo os intelectuais papel essencial em difundir as grandes obras e ideias das diversas sociedades nacionais. Tais suposições, entretanto, ressalta Said, logo se ampliaram para além da esfera nacional, a fim de abarcar ideais de um universalismo objetivista. ${ }^{2} \mathrm{O}$ papel do intelectual, nessa perspectiva, seria reproduzir certa "consciência do mundo", tornando a cultura instrumento de elevação e refinamento.

O novo humanismo proposto por Said, diferentemente, não deveria expressar transcendência em relação às especificidades de cada sociedade, buscando definir uma direção secular e materialista, ressaltado o fato de que as ações e a história não são elaborados por processos naturais, nem por forças coletivas impessoais e abstratas (Said, 2007b: 35). Um dos problemas mais evidentes do humanismo tradicional seria a defesa restrita de valores europeus, que evidenciam, na verdade, circunstâncias geoestratégicas da política internacional. Não por acaso, nas obras tidas por referenciais da humanidade há poucas referências a questões de gênero, colonialismo, escravidão ou racismo, temas que problematizariam as valorizações eurocentradas (Said, 2007b: 6I-62). Nesse sentido, a crítica secular em relação às representações nacionais ou transcendentes do humanismo tradicional deve ter em conta a multiculturalidade e o necessário cosmopolitismo da condição social. A questão da identidade nacional, especialmente, torna-se problemática, sendo papel do intelectual mostrar que as fronteiras refletem um objeto construído, por vezes inventado, o que implica contestar suas imaginações binárias e estáticas. Para além de seu caráter normativo, o problema central do "orientalismo", por exemplo, seria exatamente conceber uma realidade complexa e dinâmica como uma essência homogênea portadora, em geral, de traços negativos.

Fundamental seria questionar o conhecimento pautado por oposições binárias, mostrando novos alinhamentos sociais desconectados de fronteiras e noções essencialistas. Segundo Said (2007b: 68), um caso exemplar de análise crítica a essencializações seria o questionamento dos estudos afro-americanos em relação a concepções identitárias nacionais. Tal direção cosmopolita, dependente de uma reflexividade secular e comparativa, aparece contraposta à tendência resultante do imperialismo e do nacionalismo em separar, classificar e hierarquizar culturas distintas. Por conseguinte, a concepção de identidade requer redefinição, principalmente a imaginação da existência, tida por uma realidade autoevidente, de um "nós" e um "eles", cada qual bem definido e transparente. Em parte devido ao próprio movimento econômico e social do imperialismo, paradoxalmente, as culturas não podem ser pensadas como entidades exclusivas, sendo caracterizadas pela interdependência, pelo hibridis- 
mo e heterogeneidade. Por isto, o que Said denomina "modelo da partilha", baseado em separatismos e nacionalismos que definem rubricas redutoras, aparece cognitivamente e politicamente problemático. A tarefa política central, e do intelectual em particular, seria universalizar os conflitos e as crises, resgatando-se certo legado da filologia de se ter hospitalidade em relação ao outro não familiar.

Nota-se, portanto, que a concepção de humanismo secular de Said diferencia-se de recepções de sua teoria, e do pós-colonialismo em geral, que definem novas dicotomias ou binarismos entre teorias eurocêntricas e periféricas. Diferentemente de outras análises já elaboradas sobre o autor, o exame aqui empreendido pode sinalizar que suas teses, quando supõem metodologia comparativa e a apropriação crítica de trabalhos exemplares do pensamento ocidental, não sugerem a valorização exclusiva de perspectivas periféricas, que deveriam, então, ser contrapostas às formas de pensamento do "Centro". Tanto uma perspectiva quanto a outra teriam suas limitações referentes à inserção em contextos e tempos diferentes, que não indicam, todavia, planos epistemológicos mais ou menos vantajosos. Contestar as representações e essencialismos teóricos requer refletir criticamente e criativamente sobre diversas tradições intelectuais, sem marcar fronteiras e partilhas valorativas.

Busco mostrar, entretanto, que a tarefa crítica fundamentada por Said não é simples, nem desprovida de tensões. Por um lado, defendo que sua proposta cosmopolita explicita de forma original e profícua relações do saber com o poder, se contrapondo a tendências de padronização do imaginário, sobretudo as nacionais. Por outro, argumentarei que há dois pontos centrais que parecem necessitar melhor reflexão na definição cosmopolita do humanismo secular de Said. Em primeiro lugar, debato até que ponto Said consegue se desvincular, de fato, da tradição humanista à qual busca se contrapor. Sustento que, supondo uma razão livre que pode se afirmar autonomamente, se reproduzem algumas proposições do humanismo clássico, além de uma concepção enviesada de cosmopolitismo. Em segundo lugar, considero bases discursivas e de solidariedade social de arranjos políticos nacionais que seriam potencialmente produtivas e que não teriam sido observadas por Said, dimensões ainda não satisfeitas em organizações transnacionais.

A fim de desenvolver tais argumentos, apresento, inicialmente, a discussão da relação entre o conhecimento, desejo e poder proposta por Said, expondo as dificuldades que formas de resistência e pensamentos libertários ou cosmopolitas devem enfrentar. Posteriormente, mostro as características centrais do humanismo secular definido pelo autor, sobretudo as contraposições de certo papel do intelectual e do exílio em relação a identidades coesas e fechadas, particularmente as nacionais. Por fim, busco analisar algumas imprecisões e tensões da crítica de Said, além de notar virtudes de sua reflexão na 
abordagem da cultura e da política. A intenção central aqui definida é defender que a proposta cognitiva de Said depende de uma epistemologia comparativa que, a despeito de proposições teóricas fecundas, por vezes pode gerar problemas e direções ambíguas. Na medida em que sua argumentação se situa entre o universalismo e a singularidade, entre a comparação cosmopolita e a diferença, a proposta de Said pode acabar reproduzindo alguns problemas da perspectiva humanista tradicional.

\section{CONHECIMENTO E PODER: SABER, DESEJO E REPRESENTAÇÕES}

Segundo Said, o humanismo cosmopolita ${ }^{3}$ não se forma em um ambiente intelectual desprovido de imperativos. Para além das influências do humanismo tradicional, notam-se condicionamentos epistêmicos exercidos por certas relações conjunturais entre saber e poder, o que revela estruturas de pensamento que condicionam as práticas reflexivas por meio de modos predeterminados de apreensão. Um pensamento crítico, por sua vez, deve questionar os fundamentos das representações hegemônicas, algo complexo tendo em conta que estas são geradas por vontade de saber que se desdobra em várias instituições e busca controlar as práticas dos indivíduos. Tais representações, bem-sucedidas socialmente, reproduzem identificações predeterminadas e fixas, dentre as quais se destaca o imaginário nacional que tantos problemas pode gerar a uma reflexão cosmopolita.

Nota-se que as primeiras obras de Said são, de forma explícita, devedoras da noção foucaultiana de discurso (Said, 2007a: 29). Quando define o orientalismo como estilo de dominação, o autor quer justamente observar o deslocamento encadeado da descrição e observação de sociedades para a colonização e governo das mesmas. A importância da concepção de discurso refere-se ao fato de possibilitar perceber que os fatos ou objetos analisados aos quais o pensamento se refere não são realidades inertes, mas entidades que, em grande parte, são vinculadas a um imaginário e vocabulário que lhes dão realidade e presença, pois "as realidades de poder e autoridade - assim como as resistências oferecidas por homens, mulheres e movimentos sociais a instituições, autoridades e ortodoxias - são as realidades que tornam os textos possíveis, que os entregam aos leitores, que solicitam a atenção dos críticos" (Said, I983: 5, tradução minha).

Tal incorporação da dimensão discursiva em Said demarca, mesmo implicitamente, a trajetória de toda a sua obra. Em várias passagens (ver Said, 2007a: 40-4I; I993: xii), o autor questiona teses que vinculam, diretamente ou exclusivamente, o saber a interesses ou posições econômicas específicas. Mesmo atentando para a importância da dimensão econômica, Said não supõe a determinação desta sobre o plano das ideias, de modo que os discursos 
envolveriam, além das intenções instrumentais, intercâmbios com vários tipos de poder, como o político, cultural, intelectual e moral. Tais intercâmbios não obedeceriam a uma relação causal, sendo a articulação entre conhecimento e política definida por circunstâncias históricas múltiplas. A "luta pela geografia" que define práticas imperialistas e de poder seria complexa e interessante por não se restringir a aspectos militares ou realistas, mas envolver ideias, imagens e representações, sobretudo as que supõem povos e territórios que precisam e pedem dominação (Said, I993: 9). Uma reflexividade secular deveria, portanto, buscar questionar as representações hegemônicas elaboradas nas esferas institucionalizadas do saber, o que pressupõe não separar uma esfera cultural vista como apolítica em relação a outra esfera, tida verdadeiramente por política. O orientalismo, por exemplo, teria sido resultado da realidade cultural das sociedades europeia e norte-americana, articulada, então, aos interesses de apropriação exclusiva de novos mercados e ampliação das fronteiras para os excedentes de capital. Assim, o orientalismo seria, antes,

a elaboração não só de uma distinção geográfica básica [...], mas também de toda uma série de "interesses" que, por meios como a descoberta erudita, a reconstrução filológica, a análise psicológica, a descrição paisagística e sociológica, o Orientalismo não só cria, mas igualmente mantém; é, mais do que expressa, uma certa vontade ou intenção de compreender, em alguns casos controlar, manipular e até incorporar o que é um mundo manifestadamente diferente (Said, 2007a: 40-4I, grifos do autor).

Tal passagem, que articula o conhecimento a uma volição, é representativa de um dos temas centrais de Said: o vínculo entre saber, e da cultura em geral, em relação ao desejo e ao poder. É este vínculo - um "exercício de força cultural" (Said, 2007a: 74) baseado em estudos e governo - que busca inserir, por exemplo, o Oriente em aulas, no tribunal, na prisão e nos manuais. De modo geral, a cultura, entendida como sistema de descrição e representação do mundo - incluídos tanto o saber popular quanto as disciplinas científicas e especializadas -, tem como um dos seus objetivos centrais o prazer (Said, I993: xii). No mesmo sentido, quando a cultura se reflete em saberes institucionalizados, pode-se perceber prazer no uso do poder, desejo de observar e controlar (Said, I993: I3I). Mesmo a ação de resistência teria por parâmetro uma vontade, ou "contra-vontade", que pode transformar, por sua vez, movimentos libertários em conservadores, algo exemplificado, segundo Said (2001a: I88-I89), em vários arranjos políticos nacionalistas pós-independência. Nesses casos, a vontade é transformada em desejo de ter alguma identidade ou estabelecer uma política identitária, em si mesma controversa. Assim, em vez de um desejo de resistir e compreender que tem em vista o alargamento de horizontes, manifesta-se a busca de conhecimento por razões de controle e dominação (Said: 2007a: I5). 
A relação entre a vontade de saber e o poder é um dos aspectos centrais da apropriação de Said da obra de Foucault, desdobrando-se na reflexão da relação dos sistemas de pensamento com certas instituições. Os discursos e disciplinas de tais sistemas criam coerções produtivas, e não meros mecanismos inibidores ou repressivos. O que importa aqui destacar, particularmente, é que os discursos tanto manifestam o desejo quanto são objetos de desejo (Foucault, 200I: Io). Neste sentido específico, o desejo reflete uma "vontade de verdade", um procedimento de exclusão e supressão do "falso" que se apoia sobre uma base institucional que circunscreve a dimensão da reflexão em torno de certas categorias. Tal vontade, por vezes, expressa aproximações e presenças constantes definidas por exames e investigações, de modo que, através da dupla incitação do prazer e do poder, os controles vigilantes são reforçados pelos prazeres e pelas emoções que incitam (Foucault, I993: 44-45). Fundamental observar em tal apropriação da relação entre vontade, saber e poder de Foucault - notando-se ainda uma clara inspiração nietzscheana do tema, tendo em conta noção similar de vontade interna que se reflete em relações de forças e desejo de poder - o registro de processos políticos de afirmação de verdades, que definem, se deve notar, tanto a configuração de poder gerada pelas representações quanto os problemas que a alternativa de um pensamento crítico e secular deve enfrentar.

Dado que os discursos são objeto de desejo, já que envolvem poder, pode-se perceber também algo imanente na luta para desafiar arranjos representativos hegemônicos. Outro aspecto central na argumentação de Said é a ênfase na capacidade de resistência e de reflexão crítica que o conhecimento pressupõe, algo que se revela como desejo de se opor a certos tipos de dominação. Se há uma relação direta entre o saber e a sistematização de representações que condicionam a vida dos indivíduos, também há a potencialidade de o trabalho teórico e imaginário criar saídas para as manifestações de poder e imperialismo. Said faz uma crítica das análises que supõem uma ordem dominante que determinaria as condições do pensamento. A própria perenidade do trabalho crítico indicaria a viabilidade de formas de pensamento autônomas e alternativas. Como salientado na obra de Raymond Williams (apud Said, I983: 240), nenhum contexto de poder esgotaria a experiência social, de modo que é neste espaço intermediário que pode se situar um pensamento crítico, voltado para a observação de resistências e dos limites das representações teóricas, algo a ser notado tanto nos âmbitos especializados do conhecimento quanto nas margens das sociedades.

Deve-se notar que a crítica de Said a teorias totalizantes inclui a percepção de certos problemas presentes na obra de Foucault (Said, I983: 243-247; 200Ib: I38-I39). A despeito dos elogios que faz ao pensador francês em vários trabalhos, Said assinala a sua incapacidade de prever saídas e resistências. ${ }^{4}$ O fundamento de tal imprudência teórica seria a transposição efetuada por 
Foucault de contextos e estudos circunscritos - delimitados espacial e temporalmente - para o exame da sociedade como um todo ou de qualquer realidade social: "é quando a linguagem de Foucault se torna geral [...] que o seu avanço metodológico se transforma em uma armadilha teórica" (Said, I983: 244 , tradução minha). Nesse sentido, o principal problema da teoria foucaultiana seria a celebrada - e tantas vezes mal interpretada - tese de que o "poder está em todo lugar", o que torna a relação saber-poder soberana, saturada e inquestionável.

É a possibilidade da crítica, vinculada às instâncias de resistência e conflito que permeiam as sociedades mesmo com a força das representações e de pensamentos homogeneizadores, que sugere uma nova abordagem do pensamento e do papel dos intelectuais. Estes podem inscrever-se politicamente nas brechas dos processos hegemônicos da representação. Ressaltando a possibilidade de intervir nas formas de hierarquização e classificação identitária, Said aponta para as ambivalências da relação cultura-política, no sentido de tanto revelar o poder das representações quanto o potencial de emancipação. Embora o conhecimento se vincule à vontade e ao poder, as capacidades reflexivas, se críticas, não tendem necessariamente a uma impotência ou distanciamento improdutivo. Uma das saídas de Said é valorizar uma nova forma de conhecimento cosmopolita e secular, em que a condição de exilado serviria, metaforicamente, para retratar a capacidade de desafiar fronteiras ou identidades predeterminadas. Dentre as identificações contestadas, destacam-se as nacionais, representações paradigmáticas dos essencialismos que devem ser refutados por nova perspectiva humanista.

\section{O HUMANISMO SECULAR COMO COMPARAÇÃO E A QUESTÃo NACIONAL}

Se tivéssemos que destacar uma questão específica de Said a respeito das potencialidades de um conhecimento que consiga unir o desejo do saber a uma perspectiva crítica e libertária, um dos temas obrigatórios seria a relação entre um intelectual virtuoso e o questionamento de identidades fechadas, em especial a nacional. O desejo de interpretar e conhecer deveria, então, ser canalizado de modo a fundamentar o questionamento às representações hegemônicas. Fazendo referência ao conceito de "pensamento identitário" de Adorno, o autor (Said, 2007b) vincula o imaginário nacional ao imperialismo, à tese de grandes civilizações em confronto e aos entusiasmos religiosos, tendências antisseculares e antidemocráticas. Nada mais significativo ao desafio do padrão universal buscado por Said do que a problemática do intelectual, sujeito inscrito de modo medular em laços históricos e nacionais. Assim, o pensamento deveria resgatar a formação histórica das sociedades, definidas, ao contrário do que frequentemente se veicula, por identidades 
diversas e heterogêneas, ainda mais visíveis na contemporaneidade caracterizada por vastos fluxos migratórios e demandas políticas de novas identidades. Reproduzir discursos nativistas que reivindicam autenticidade e coesão acarretaria limitações rígidas e possível exclusão de vários grupos sociais (Said, 2007b: 70).

Buscar desvencilhar-se dos hábitos rígidos do nacionalismo requer também questionar representações tradicionais de unidades identitárias que seriam culturalmente coesas. Na medida em que a nação é um objeto construído, por vezes inventado, o intelectual deve ressaltar suas tensões e conflitos, destacando que o processo de identificação é problemático em si mesmo, dado que tende a violar outras identidades minoritárias presentes em um mesmo contexto social (Said, 200Ib: I30). Deve-se, portanto, negar a direção do humanismo clássico que toma a dimensão cultural como fonte de identidade, pregando retornos a tradições nacionais inertes. O problema de tal postura intelectual é a proposição de códigos rigorosos de conduta que diferenciam, explícita ou implicitamente, um "nós" e um "eles", quase sempre com algum grau de xenofobia (Said, I993: xiii).

Said (I993: 2I3-2I4) representa os problemas do condicionamento nacional por meio das interpretações e versões pós-coloniais de A tempestade, de Shakespeare, sobretudo as latino-americanas. Em relação à escolha de tomar Caliban ou Ariel como referenciais de conduta, Said mostra como a melhor alternativa, indicada, por exemplo, nas obras de Frantz Fanon e Roberto Retamar, é destacar a conexão efetuada por Caliban entre a sua história nacional e a história de dominação de vários outros territórios e nações. A questão é constituir um novo imaginário que descarta o retorno a um nativo subordinado e servil a Próspero, baseando-se na subjetividade complexa de Caliban, que se volta ou para o desenvolvimento futuro e híbrido ou para a descoberta, problemática, de uma essência pré-colonial. Nesse sentido, representa-se a alternativa de se construir uma postura intelectual consciente dos perigos da xenofobia e de concepções homogeneizadoras. Said recupera, portanto, o argumento geral de Fanon (1979) de que o espaço da nação nunca seria horizontal, o que indica a necessidade de se contestar teorias orgânicas de coesão e totalidade social. A resistência cultural de novas imaginações nacionais, sobretudo as pós-independência, deveria constituir memória comunal original e outra formulação histórica, indicando o potencial de representações coletivas abertas e autocríticas, fundamentadas em um "desequilíbrio oculto" que gera, constantemente, reflexividade e renovação (Fanon, I979: I88). O importante é que tais representações não devem ser presas a particularismos que buscam descobrir a "verdade de um povo".

Segundo Said (2005: 35), entretanto, todo pensamento reflete o dilema entre o alinhamento e a solidão, ou, de forma mais geral, entre a inscrição do pensamento em uma realidade social que lhe é anterior e a possibilidade 
de parâmetros críticos universais. O conhecimento envolveria uma "formação estratégica" (Said, 2007a: 50), dado que os textos estão relacionados a um conjunto específico de produção textual, públicos e instituições condizentes com um poder referencial que, em parte, direciona as reflexões. Ao lado da possibilidade de um conhecimento cosmopolita e plural, haveria um nível cognitivo caracterizado pela "mundanidade" (Said, 2007b: 7I e 84-85) que condiz com certa "contaminação" e envolvimento, sobretudo em relação ao poder e a interesses específicos, algo que o orientalismo teria sido exemplar como resultado de um interesse do Ocidente em relação ao Oriente. A questão nacional já expressa tal problema intelectual, dada a conveniência do uso de determinada língua na prática do conhecimento. Além disso, Said (2005) nota como o dilema envolve a contraposição referente aos papéis de intelectual profissional e intelectual público. Diferindo das proposições de Gramsci, o autor questiona vínculos de classe ou defesas de interesses particularistas. $\mathrm{Na}$ medida em que o pensamento deve confrontar dogmas e ortodoxias, deveria haver independência em relação a quaisquer grupos, corporações ou governos, sob pena de se reproduzir um pensamento "corporativo" (Said, 2005: 43) ou "profissional" (Said, 2005: 78). Enquanto o intelectual corporativo apenas reproduz aspectos de uma identidade desproblematizada, o profissional sintetiza o pensamento apropriado e comercializável que encontra sua legitimidade na figura do especialista.

Em contraponto ao nacionalismo e a representações intelectuais redutoras, a condição de exílio, segundo Said, seria exemplar em manifestar a capacidade fecunda da multiculturalidade em criar novos tipos de conexões. Em vez de gerar esquecimento ou expatriados, o exílio significa uma forma exemplar de mediação, pois estimula experiências que atravessam fronteiras culturais e desafiam limitações nativistas. A condição do exílio constitui, então, uma alternativa ao legado negativo do imperialismo em difundir crenças exclusivistas e inertes. Além disso, a condição cognitiva do exilado seria exemplar para o rompimento de cadeias representativas que geram um alter ego concorrente, baseado no estabelecimento e reprodução de identidades opostas, os "outros", que seriam inexoravelmente díspares (Said, 2007a: 44I).

O exilado tem de enfrentar um estado intermediário em que não é nem devidamente integrado ao seu novo lugar, nem completamente livre do antigo, de modo que vive, necessariamente, de envolvimentos e distanciamentos, o que previne tanto um pensamento corporativo quanto profissional. Tal como expresso nos exemplos de Adorno, Auerbach e C. L. R. James, o essencial é que, sobretudo em contraposição às limitações da nação, o exílio reflita uma dissonância em relação ao contexto social vivido, de modo que não se perca em suas próprias dificuldades, como a distância de textos, tradições e continuidades que constituem a rede da cultura (Said, I983: 6). O "judeu não-judeu", tal como definido por Isaac Deutscher, com sua utopia de uma 
sociedade internacional de iguais, desvinculada da ortodoxia de nacionalismos judeus ou não-judeus, também representaria a fecundidade de uma situação desalojada e diaspórica que se volta para a pluralidade e para o cosmopolitismo (Said, 2004: 80-82).

Said (2005: 60), porém, toma tal situação não como uma condição real, mas metafórica, não se referindo exclusivamente a condições reais de deslocamento e migração. O exílio seria representativo da uma condição cognitiva que está além da geografia e de suas predeterminações identitárias, envolvendo um trabalho intelectual transnacional que se articula a um pensamento e interpretações efetivamente seculares (Said, 200Ib: I3I). Contrariamente à unidade e coesão que perpassam os ideais da nação e as representações de identidade de grupos e classes, o exílio condiz com uma fragmentação e descontinuidade que, longe de acarretarem dificuldades, são fecundas. Assim, a condição exilada não supõe um grande retorno a origens supostamente perdidas que se contrapõem a "outros".

O exílio exposto por Said reflete a crítica das amarras que a dimensão cultural, com seus padrões esquematizados de representações e suas divisões entre algo que lhe é intrínseco ou extrínseco, impõe aos indivíduos. A cultura, neste sentido, aparece como esfera de um exercício de poder difuso, a refletir padrões de autoridade e interdição, um "ambiente, processo e hegemonia nos quais os indivíduos (em suas condições particulares) e seus trabalhos estão encaixados, como se supervisionados, pelo alto, por uma superestrutura e, na base, por toda uma série de atitudes metodológicas" (Said, I983: 8, tradução minha). É contra a força da reprodução da hegemonia cultural, baseada, sobretudo, na imposição de uma ideia de pertencimento e localização que se reflete no imaginário nacional, que a prática intelectual deve resistir. Tal resistência, porém, só se pode efetivar caso seja parcialmente transcendido o conjunto de representações reproduzido pelo Estado-nação e pela cultura nacional. A crítica envolve certa distância, de modo a se questionar a dimensão confortável, quase religiosa, que a cultura provê quando nos separa e nos distingue de "outros". A consciência crítica, mais particularmente, deve atentar para o fato de estar situada entre duas tentações (Said, I983: I6-26), a primeira relacionada com vínculos de "filiação" de nascimento e nacionalidade, e a segunda articulada a sistemas de pensamento construídos e adquiridos por "afiliação" que, não obstante, representam apenas uma substituição compensatória da autoridade e hierarquias das ligações filiais naturalizadas.

Dada a incapacidade de um distanciamento completo dos valores e normas culturais, Said desenvolve a proposta de uma metodologia comparativa como forma de desenvolver a consciência crítica. O caráter positivo da condição de exílio provém da possibilidade de uma base epistemológica que compara diversas perspectivas. O exílio seria, portanto, a condição ideal de 
se buscar uma justaposição de horizontes para produzir uma tomada de posição secularista em que vários lados e tendências de uma questão são levados em conta, pois "a tarefa do humanista não é apenas ocupar uma posição ou um lugar, nem simplesmente pertencer a algum local, mas antes estar ao mesmo tempo por dentro e por fora das ideias e valores circulantes que estão em debate na nossa sociedade, na sociedade de alguma outra pessoa ou na sociedade do outro" (Said, 2007b: IOI). Tal justaposição pode possibilitar profícua comparação entre alternativas teóricas, além de questionar tradições de pensamento que se portam como dogmas culturais quando apropriadas por instituições e grupos ou outros contextos sociais (Said, I983: 246-247). O interessante seria medir a distância temporal e espacial das teorias, assim como perceber resistências em relação às mesmas em contextos diversos. A recepção envolve, então, um tratamento provisório dos textos, buscando elucidar questões obscuras e suas estruturas de sentimento (Said, 2007b: 85).

A perspectiva comparativista reflete uma epistemologia descentralizadora que, por intermédio de um espírito diaspórico, pode revelar como as histórias são quase sempre híbridas e descontínuas. Said (2004) exemplifica tal direção com Freud em Moisés e o monoteísmo, que teria percebido como a própria identidade judaica não teve início em si mesma, dado que teria sido fundada por um não-judeu, além de se basear no monoteísmo egípcio. Tal percepção só poderia ser possível por um pensamento em perspectiva que, distanciado da episteme e métodos hegemônicos, se dispõe a examinar comparativamente outras histórias, no caso uma história não-europeia e não-judaica. Os reflexos políticos de não se assumir tal perspectiva histórica seriam notórios, envolvendo o esquecimento e subordinação de identidades em benefício de outras tidas por centrais ou superiores. A comparação, portanto, é uma etapa necessária para a desconstrução das narrativas de partilha reproduzidas nos discursos nacionalistas, possibilitando uma saída a noções que manifestam incompatibilidades "naturais" e histórias separadas.

Said, neste sentido, alia a sua noção de diáspora a outras reflexões (ver Hall, 2009: 25-48) que não sugerem conceitos baseados em fronteiras de separação entre identidades, mas que observem formas sincretizadas de imaginação fundamentadas em significados relacionais. O pensamento exilado reflete perspectivas diaspóricas da cultura que subvertem imagens homogeneizantes, sobretudo as nacionais com suas narrativas de origem, mas também as multiculturalistas que supõem processos coesos de identificação. Tal direção pode ser percebida em Paul Gilroy (2008: I5), que propõe, metaforicamente, uma abordagem não apenas relacionada com a terra - solo das culturas nacionais -, mas com o mar que se movimenta, conecta pontos distantes e indica culturas mais fluidas e menos fixas, o que expressa um "desejo de transcender tanto as estruturas do Estado-nação como os limites da etnia e da particularidade nacional" (Gilroy, 2008: 65). Pode ser notada 
também nos argumentos de Homi Bhabha (1994) a respeito de hibridismos que ocupam um "terceiro espaço", desvinculado das clivagens culturais tradicionais. Além de modos transversais e híbridos de relacionamento social, o olhar em exílio possibilitaria observar adequadamente formas de dominação que não se restringem a fronteiras nacionais.

Segundo Said (2005: 25), um pensamento secular teria "vocação para representar", articulando uma mensagem intencionalmente dirigida a um público amplo, não demarcado a priori. A universalidade de tal procedimento contrapõe-se tanto ao papel de funcionário do pensador profissional quanto ao comprometimento corporativo em relação a uma associação ou grupo político. O essencial é nunca reduzir o ceticismo em prol do conformismo, da mesma forma que transformar o desejo de compreensão em manifestações de desejo de controle e dominação. Said propõe um entendimento analítico baseado na coexistência e "alargamento de horizontes" (Said, 2007a: I5), algo que pode ser bem representado na utopia geral da universidade como campo, em certo sentido, de integração e suspensão de dispositivos de poder e de separatismos (Said, 200Ia: I90).

\section{ENTRE A REFLEXIVIDADE E AS CONDIÇÕES HISTÓRICAS: HUMANISMO COSMOPOLITA E SEUS LIMITES}

Buscando defender um conhecimento comprometido com a crítica e com a liberdade, Said (2005: 3I; 2007a: 463) critica argumentos pós-modernos que concebem a substituição de grandes narrativas por jogos de linguagem ou situações locais que refletiriam o inexorável caráter contingente e não histórico das novas relações sociais. Além disso, particularmente em relação ao campo dos estudos literários, o autor questiona algumas alternativas desconstrucionistas que se desconectam de tendências emancipatórias ou as celebrações nostálgicas de um passado fixo presente nas formas tradicionais do humanismo. Como resposta a tais tendências, busca-se a reconstrução das potencialidades do esclarecimento, destacando o imperativo político e histórico do próprio fazer teórico.

A perspectiva secular de Said não propõe, porém, um roteiro político predeterminado e ordenado, preferindo seguir a crítica do pensamento pós- colonialista a temporalidades desenvolvimentistas ou a tipos de "domesticação da política" (ver Chakrabarty, 2008) que retiram dos homens a responsabilidade de direcionarem de forma autônoma seu futuro. Said constrói, antes, uma argumentação mais crítica do que propositiva, indicando especialmente os perigos de os movimentos libertários se circunscreverem ao fomento de identidades fechadas e seus pressupostos de homogeneidade e separatismo. Quando se articula a dimensão da identidade com a da liberdade ou resistência, 
aquela "não pode ser pensada nem trabalhada em si mesma; ela não pode se constituir nem sequer se imaginar sem aquela quebra ou falha original radical que não será reprimida" (Said, 2004: 82). Assim, como sugere um autor próximo, "ao aderir à diáspora, a identidade pode ser [...] levada à contingência, à indeterminação e ao conflito" (Gilroy, 2008: I9). Em vez de demarcar as saídas precisas que os movimentos de resistências têm de seguir, Said prefere ressaltar a abertura que as imaginações culturais e políticas devem expressar. Neste sentido específico, o autor parece seguir análise similar a de Homi Bhabha (I994) a respeito da ambivalência das identidades, sobretudo de representações nacionais ou nativistas. ${ }^{5}$ Torna-se relevante observar o caráter instável das representações, sobretudo devido à imposição da temporalidade do entre-lugar (in-between), referente à heterogeneidade da população, a suas minorias e a seus locais tensos de diferença cultural. A questão essencial é que, até mesmo em momentos de resistência, a narrativa pedagógica das identidades, constituindo teorias de homogeneidade e horizontalidade, tende a ocultar a instabilidade da significação cultural.

Especificamente em relação ao pensamento crítico, cabe notar, entretanto, algumas tensões na tendência universalista do cosmopolitismo de Said. Ainda que haja, por vezes, referências às circunstâncias sociais que, necessariamente, cercam o pensamento, delimitando-o espacial e temporalmente, um problema reside em teses otimistas do autor sobre a possibilidade de um "desvendamento genuíno" (Said, 2007a: I9) ou de uma tentativa de "falar a verdade ao poder" (Said, 2005: I5). Said não é preciso na definição dessas noções, apontando certos princípios morais que serviriam de norte na tomada de decisões, objetivando uma "mudança no clima moral" (Said, 2005: I02). Por vezes, porém, chega a ser categórico, lançando mão de afirmações de que o intelectual deve "pesar cuidadosamente as alternativas, escolher a certa [...] onde possa fazer o maior bem e causar a mudança correta" (Said, 2005: I04, grifos meus). Tal imprecisão demonstra dificuldades em definir precisamente a tensão entre a subjetividade e padrões políticos e intelectuais objetivos. Para quem relaciona as teses do pensamento pós-colonialista a reflexões desconstrucionistas, e particularmente a Derrida, tais tensões, que revelam um sentido objetivista, seriam problemáticas, pois parecem reproduzir certo modelo "metafísico" (seguindo linguagem derridariana). Problemas similares também podem ser percebidos nos momentos em que Said defende um pensamento direcionado à liberdade humana (ver Said, 2005: 3I). Eles se referem, especialmente, à contradição em buscar um "conjunto de princípios mais universal e racional" (Said, 2005: 92) e, paralelamente, criticar propostas de universalização de valores baseadas na suposição de uma imparcialidade cognitiva superior e em uma postura sentimentalista em relação à humanidade (Said, 200Ib: I32-I33).

As imprecisões da resposta de Said envolvem a temática do secularismo que propõe. Por um lado, há claramente uma tentativa do autor de se 
separar de tendências cômodas que sugerem um porto seguro para o pensamento, baseado na revelação ou em textos inquestionáveis, tal como se expressa no âmbito religioso. A falibilidade seria inerente ao conhecimento, e o novo humanismo, tendo como exemplo as proposições epistemológicas de Vico, sempre portaria algo de provisório, incompleto e discutível, ou o que pode ser percebido como uma "falha trágica" (Said, 2007b: 3I). O secularismo sugere, então, liberdade e pluralidade de opinião, o que trai ideais de objetividade e autoridade intelectual. Além disso, Said (I983: 226-247; 2007b: 45-46) assinala a relação das ideias com determinados contextos sociais, o que determinaria, inclusive, vieses na recepção da obra dos autores. ${ }^{6} \mathrm{O}$ conhecimento cosmopolita trataria o cânone, por exemplo, de modo original, tal como expresso em seu sentido musical, sendo concebido como forma contrapontística que torna as leituras e interpretações abertas a novas combinações e significados. A reapropriação do passado deveria ser vinculada diretamente às condições presentes, instituindo uma releitura que não segue regras fixas, mas que se volta para a problematização de nossa própria condição, sempre aberta a diferentes direções sociais e políticas, o que, por sua vez, possibilita o desenvolvimento de identidades alternativas e princípios baseados em outro espaço que não o vivido (Said, 2007b: I05).

Por outro lado, Said adverte (2005: 94-95) que criticar as pretensas verdades do Ocidente, baseadas num ideal de objetividade científica que legitimou, e continua a legitimar, condições imperiais, não significa aceitar a incompatibilidade ou incomensurabilidade de diferentes visões do mundo. A intolerância e o dogmatismo produzem exclusões e injustiças que devem ser questionadas pelo novo pensamento secular. O desafio, portanto, deve ser buscar novos critérios de comparação, inclusive que observem características de outras culturas que estão, de forma similar, mas não explicitamente, presentes em nossas próprias realidades sociais. A questão é criticar tentativas de universalizar valores circunscritos a particularismos, como o orientalismo mostrou, definindo um conceito de justiça que admita, sem hierarquizações ou preferências, diferenças, algo que poderia ser exemplificado nas discussões de direitos humanos, normas internacionais de guerra, além das institucionalizações globais de direitos tais como os dos trabalhadores, de imigrantes e da infância (Said, 2005: 97-I00). Mais uma vez a tensão revela-se, baseada na relação entre tais normas universais e as condições particulares de cada país ou grupo social, tendo em conta seus interesses reais mais imediatos. Cabe notar que tal tensão se manifesta desde suas primeiras obras, como em Orientalismo, em que analisa o tema das representações ou "re-presenças" ocidentais sobre o Oriente a partir da suposição de que estas estariam distanciadas de uma realidade, de fato, dos países e sociedades examinados (Said, 2007a). Nos momentos em que discute as ficções ocidentais e seus deslocamentos ou exclusões dos fatos concretos, o pressuposto, em- 
bora implícito, é que haveria um Oriente a ser devidamente analisado, ainda que o próprio Said em várias passagens, refletindo certa ambivalência, argumente contra essa possibilidade.

Por conseguinte, cabe perguntar até que ponto a proposta de Said consegue, de fato, se desvincular de uma tradição humanista que aposta na necessidade de aprimoramento humano com base em um pressuposto de pensamento autônomo (ver Bauman, I998). Na medida em que Said, embora apontando limites, ainda crê nas potencialidades de uma razão livre e na capacidade de resistir e de se afirmar de forma autodeterminada, permanecem algumas suposições do projeto humanista clássico - e talvez não seja à toa que o autor continue, com base no mesmo conceito, a propor outra espécie de humanismo.7 Assim, a incorporação das temáticas da resistência e da liberdade - e cabe notar, no momento em que Said assinala certos limites em relação à obra de Foucault - parece constituir uma armadilha no sentido de supor certo privilégio do sujeito e uma aposta na busca por verdades. Consequentemente, é importante perguntar se o discurso do humanismo cosmopolita não se vincula, ao fim e ao cabo, a uma utopia marcadamente ocidental, o que implica pensar na possibilidade, seguindo os próprios termos de Said, de constituir representações que acabem por beneficiar novas narrativas de colonização.

Outra questão controversa do pensamento de Said diz respeito à falta de uma reflexão mais precisa sobre as condições estruturais de uma condição cosmopolita. Ainda que possa parecer injusta tal observação dado o vínculo disciplinar de Said com o campo da crítica literária, parece necessário aliar suas concepções a uma argumentação mais marcadamente histórica, voltada para o exame de novos fatos sociais que acarretam a desconexão entre nação, Estado e sociedade, o declínio de formas específicas de integração social e soberania ligadas aos Estados nacionais e o concomitante fortalecimento de relações cosmopolitas (Habermas, 2002: I2I-I45). Há duas questões, neste sentido, que podem ser incorporadas. Em primeiro lugar, cabe destacar a conexão de condutas cosmopolitas com o surgimento de novos problemas e riscos compulsórios de dimensões globais, o que, por sua vez, gera respostas diferenciadas por parte dos agentes. Assim, seguindo algumas proposições de Ulrich Beck (2004), por exemplo, podem-se verificar variações de cosmopolitismos vigentes, desde um passivo, relacionado com a inconsciência dos agentes da articulação de suas vidas em relação a culturas estrangeiras e aos riscos não esperados da interpendência, até um ativo - ou "perspectiva cosmopolita" - que emerge da reflexividade de que somos parte de uma lógica civilizatória de fato mundial (Beck: I34-I37). Em sentido similar, observar a diferença de um "cosmopolitismo consumista", predominante e baseado na circulação de bens culturais e pessoas, perante um fundamentado na relação consistente entre solidariedades locais e uma sociedade civil internacional 
(Calhoun, 2002: 889). O essencial, portanto, é mostrar processos e estruturas que tornam epistemologias nacionais não capazes de acompanhar mudanças sociais, de modo a não pressupor, exclusivamente, um cosmopolitanismo abstrato ou normativo-filosófico, "a noble ring in a plebeian age" (Beck \& Sznaider, 2006: 6).

Em segundo lugar, é importante perceber também variações nas formas nacionais constituídas na modernidade, de modo a não se pressupor uma direção necessariamente negativa ou contraposta a quaisquer modelos de imaginação nacional. Torna-se relevante, então, estar atento aos contextos sociais que envolvem os atores cosmopolitas, o que implica pensar em relações de localidade, tradição e nacionalidade que nem sempre são limitadoras, sendo bases de solidariedade social e discursos públicos que não encontram sustentação em instituições transnacionais contemporâneas (Calhoun, 2002: $875 ; 879-880$ ). Ainda que a ação envolva um tipo de imaginação de cultura homogênea e coesa, é importante não descartar a dimensão de soberania popular que também se relaciona com tal imagem (Breuilly, 2000: 175; Hobsbawm, 2000: 273; Smith, 2009: 6I-80). Paralelamente, importa observar, mesmo com suas notórias limitações, formas de responsividade e controle que se constituíram no âmbito nacional, ao contrário da relativa ausência de influência e autoridade que a maior parte das populações exercem em relação a novas entidades supranacionais (Skrbis, Kendall \& Woodward, 2004: 123I25). Assim, pode ser questionável, e não factível, relacionar diretamente o cosmopolitismo a um "estrangeiro universal" desvinculado de esferas políticas formais ou instituições (Baneth-Nouailhetas, 2006: 7I). A análise de Habermas (2002: I3I-I34), por exemplo, a respeito da tensão entre universalismo e particularismo que marca a experiência nacional expressa um tipo de abordagem profícua da questão na medida em que sustenta que o cosmopolitismo, caso prevaleça uma autocompreensão igualitária da comunidade jurídica, pode estar presente dentro das fronteiras nacionais. Tal compreensão cosmopolita (em seu sentido nacional) correria perigo apenas quando a coesão dos cidadãos for atribuída a um princípio originário tido por natural e presente desde sempre em determinado território e população.

Não obstante tais limites, a teoria de Said e, particularmente, a sua crítica ao pensamento humanista tradicional, apesar das imprecisões assinaladas, parece fecunda, em primeiro lugar, no sentido de apontar para as relações complexas entre a cultura e a política, sobretudo para a reflexão de um sentido pós-nacional das relações políticas. Parece, de fato, incoerente separar as dimensões da cultura e da política, com uma esfera cultural isolada tida por estática e outra política que, de fato, seria o verdadeiro local da luta de interesses, de modo que "a cultura é exonerada de qualquer envolvimento com o poder, as representações são consideradas apenas como imagens apolíticas a serem analisadas e interpretadas como outras tantas gramáticas 
intercambiáveis, e o divórcio entre passado e presente é assumido como fato" (Said, I993: 57). Tal como exposto por Gayatri Spivak (2006: 359), a cultura requer uma definição que revele um conjunto não preciso nem rígido de premissas que se encontram ativas e em movimento, ainda que constituam, em certo nível, crenças e suposições organizadas. A cultura não pode ser tida por uma instância monolítica ou estanque que determinaria os sujeitos, constituindo-se como conjunto de recursos e meios para a ação política. A definição pós-colonialista de cultura expressa por Said, que reconhece a importância das proposições de Raymond Williams (I979: 87-IO0), provê meios analíticos de exame de processos de hegemonia sem supor determinismos nas relações entre as esferas econômica, política e cultural. Se há condicionamento entre tais dimensões, este, como definido por Williams, se situa como uma "fixação de limites" que revela tanto "pressões" quanto elementos "residuais" ou "emergentes" da cultura.

Em segundo lugar, a tentativa de Said de reconstruir o esclarecimento, por meio de suas concepções de cosmopolitismo e sua epistemologia comparativa, pode ser relevante por tomar o conhecimento como processo, de modo que não há um sentido reflexivo com causas e efeitos, início e fim predeterminados, mas sim um "processo de incessante revelação, descoberta, autocrítica e liberação” (Said, 2007b: 4I). Além disso, na medida em que busca explicitar as relações saber-poder, a fecundidade de tal procedimento revela-se no momento em que se concebe novo modelo crítico de cosmopolitismo baseado na perspectiva da diferença e da condição colonial, em oposição a cosmopolitismos tradicionais da teologia, da filosofia ocidental e da economia política que fundamentaram representações imperialistas (Mignolo, 2000). A crítica do novo humanismo cosmopolita serviria, então, como contraponto a tendências de padronização e essencialização do imaginário, o que tende a provocar imagens de identidades rígidas e fixas. Nesse sentido, a proposta cognitiva de Said alcança mais consistência como crítica do que como referencial normativo. Na verdade, o que se expressa é certa ambivalência do conhecimento, a servir tanto para a predeterminação do movimento social e político quanto para a sua abertura. Said expressa posição positiva em relação ao último sentido, de modo que a vontade de saber possa se transformar em vontade crítica a perceber os limites e contratempos dos processos de identificação e representação política. 
Bruno Sciberras de Carvalho é doutor em Ciência Política pelo Instituto Universitário de Pesquisas do Rio de Janeiro (IUPERJ) e professor do Departamento de Ciência Política e do Programa de Pós-Graduação em História Comparada da Universidade Federal do Rio de Janeiro (UFRJ). Suas áreas de interesse são teoria política e teoria social. É autor de A escolha racional como teoria social e política: uma interpretação crítica (2008). 


\section{NOTAS}

I A reconstrução da capacidade racional do conhecimento proposta por Said, na medida em que se baseia na comparação de perspectivas e horizontes, dá atenção especial a grande parte da reflexão ocidental, o que mostra que o pós-colonialismo do autor está longe de descartar de modo simplista ou indistinto o pensamento construído nos grandes centros em benefício de reflexões constituídas nas periferias.

2 A fim de mostrar tal desenvolvimento do humanismo em direção a um paradigma universalista, Said (2005) enfoca proposições do crítico francês Julien Benda acerca dos intelectuais, expostas, sobretudo, no trabalho A traição dos intelectuais.

3 A seguir, passarei a tratar "humanismo secular" e "humanismo cosmopolita” como sinônimos. Ambas as concepções fundamentam uma perspectiva crítica que deve ser contraposta a representações identitárias fechadas, que assumem, segundo o autor, aspectos quase religiosos. A postura intelectual secular deve questionar sentimentos de pertencimento predeterminados - manifestados exemplarmente nas identidades nacionais -, buscando revelar o caráter histórico, complexo e mediado dos artifícios humanos. Fundamentalmente, importa observar que a crítica secular pressupõe, necessariamente, um posicionamento cosmopolita que possa romper com conexões identitárias homogeneizadas e rígidas.

4 Said (200Ib: I32-I33) faz crítica similar ao argumento de Gayatri Spivak, tida como referência nos estudos pós-colonialistas, sobre a impossibilidade de o subalterno falar. Apesar de frequentemente apontar os perigos dos nacionalismos e suas direções nativistas em vários processos de resistência, Said enumera, em várias obras, sobretudo após Cultura e imperialismo, exemplos de movimentos sociais e políticos originais que conseguiram imprimir novos imaginários em países periféricos.

5 Entretanto, ao contrário da suposição de Bhabha (I994: 2-3) de uma relativamente livre articulação das diferenças culturais fundada em "entre-lugares", contraposta aos aparelhos pedagógicos, Said prefere usar o termo "resistência" para indicar os processos políticos de questiona- 
mentos das representações hegemônicas. Tal indicação de Said sugere que as representações, manifestadas por relações de poder constituídas historicamente, dificilmente podem ser desbaratadas de forma simples. No mesmo sentido, embora incorporando postulados críticos similares, Said também distancia-se das suposições libertárias performáticas e não textuais esboçadas por Gilroy (200I).

6 Said (1983: 226-247) trata, por exemplo, de como a teoria de Lukács teria sido domesticada em sua recepção, via Lucien Goldmann, no contexto intelectual francês. Tal domesticação, perceptível na passagem da concepção de uma "consciência insurrecional" para "visão trágica", seria resultado da especificidade de situações sociais que implicam pressões e limites para o pensamento.

7 Sobre as relações e oposições entre o humanismo e o pensamento pós-colonialista em geral, ver Gikandi (2004).

\section{REFERÊNCIAS BIBLIOGRÁFICAS}

Baneth-Nouailhetas, Émilienne. (2006). Le postcolonial: histoires des langues. Hérodote: Revue de Géographie et de Géopolitique, I20, p. 48-76.

Bauman, Emily. (I998). Re-dressing colonial discourse: post-colonial theory and the humanist project. Critical Quarterly, 40/3, p. 79-89.

Beck, Ulrich. (2004). Cosmopolitan realism: on the distinction between cosmopolitanism in philosophy and the social sciences. Global Networks, 4/2, p. I3I-I56.

Beck, Ulrich \& Sznaider, Natan. (2006). Unpacking cosmopolitanism for the social sciences: a research agenda. British Journal of Sociology, 57/I, p. I-23.

Bhabha, Homi. (I994). The location of culture. Londres: Routledge.

Breuilly, John. (2000). Abordagens do nacionalismo. In: Balakrishnan, Gopal (org.). Um mapa da questão nacional. Rio de Janeiro: Contraponto.

Calhoun, Craig. (2002). The class consciousness of frequent travelers: toward a critique of actually existing cosmopolitanism. The South Atlantic Quarterly, IoI/4, p. 869-897. 
Chakrabarty, Dipesh. (2008). La historia subalterna como pensamiento político. In. Estudios Postcoloniales. Ensayos Fundamentales. Madri: Traficantes de Sueños.

Fanon, Frantz. (I979). Os condenados da Terra. Rio de Janeiro: Civilização Brasileira.

Foucault, Michel. (200I) A ordem do discurso. São Paulo: Loyola.

Foucault, Michel. (1993). História da sexualidade I: A vontade de saber. Rio de Janeiro: Graal.

Gikandi, Simon. (2004). Poststructuralism and postcolonial discourse. In: Lazarus, Neil (org.). The cambridge companion to postcolonial literary studies. Cambridge: Cambridge University Press.

Gilroy, Paul. (200I). O Atlântico negro: modernidade e dupla consciência. São Paulo: Ed. 34.

Habermas, Jürgen. (2002). A inclusão do outro. Estudos de teoria política. São Paulo: Loyola.

Hall, Stuart. (2009). Da diáspora. Identidades e mediações culturais. Belo Horizonte: Ed. UFMG.

Hobsbawm, Eric. (2000). Etnia e nacionalismo na Europa de hoje. In: Balakrishnan, Gopal (org.). Um mapa da questão nacional. Rio de Janeiro: Contraponto.

Mignolo, Walter. (2000). The many faces of cosmopolis: border thinking and critical cosmopolitism. Public Culture, I2/3, p. 72I-748.

Said, Edward. (2007a). Orientalismo. O Oriente como invenção do Ocidente. São Paulo: Companhia das Letras.

Said, Edward. (2007b). Humanismo e crítica democrática. São Paulo: Companhia das Letras.

Said, Edward. (2005). Representações do intelectual. As conferências Reith de I993. São Paulo: Companhia das Letras.

Said, Edward. (2004). Freud e os não-europeus. São Paulo: Boitempo.

Said, Edward. (2001a). Culture and imperialism. In: Viswanathan, Gauri (org.). Power, politics, and culture. Interviews with Edward Said. Nova York: Vintage Books.

Said, Edward. (200Ib). Criticism and the art of politics. In: Viswanathan, Gauri (org.). Power, politics, and culture. Interviews with Edward Said. Nova York: Vintage Books. 
Said, Edward. (1993). Culture and imperialism. Nova York: Vintage Books.

Said, Edward. (1983) The world, the text, and the critic. Cambridge: Harvard University Press.

Skrbis, Zlatko; Kendall, Gavin \& Woodward, Ian. (2004). Locating cosmopolitanism: between humanist ideal and grounded social category. Theory, Culture \& Society, 2I/6, p. II5-136.

Smith, Anthony. (2009). Ethno-symbolism and nationalism: a cultural approach. Nova York: Routledge.

Spivak, Gayatri. (2006). Culture alive. Theory, Culture \& Society, 23/2-3, p. 359-360.

Williams, Raymond. (I979). Marxismo e literatura. Rio de Janeiro: Zahar. 


\section{ENTRE O UNIVERSALISMO E A CONDIÇÃO CONTEXTUAL: CONCEPÇÕES E LIMITES DO HUMANISMO SECULAR DE EDWARD SAID}

Resumo

O trabalho analisa o "humanismo secular" de Edward Said, que busca ir além do provincianismo e de contraposições hierarquizadas que caracterizariam o humanismo tradicional. Refletindo aspectos da abordagem pós-colonialista, questionam-se identidades fixas e excludentes, destacando as minorias e a fluidez de identidades opostas a representações hegemônicas. Tendo em conta virtudes cognitivas de um novo humanismo, Said faz referências à condição de exílio, exemplares em manifestar a capacidade fecunda de se criar novos tipos de conexões e percepções sociais. O artigo busca mostrar virtudes e limites do conhecimento cosmopolita proposto por Said, destacando alguns impasses de sua teoria em relação a aspectos da tradição humanista.

\section{BETWEEN UNIVERSALISM AND CONTEXTUAL CONDITION: CONCEPTS AND LIMITS OF THE SECULAR HUMANISM OF EDWARD SAID}

ism. Reflecting aspects of post-colonialists approaches, Said questions notions of fixed or exclusionary identities and emphasizes the minorities and the fluidity of identities opposed to hegemonic representations. Taking into account cognitive vantages of a new humanism, Said makes references to the condition of exile that would be exemplary to express the ability to create new types of social connections and insights. The article points out virtues and limits of the cosmopolitan knowledge proposed by Said and it highlights some impasses of his theory in relation to aspects of the humanist tradition.

\section{Palavras-chave}

Edward Said; Humanismo secular; Pós-colonialismo; Cosmopolitismo; Nação.
Keywords

Edward Said; Secular

humanism; Post-

colonialism;

Cosmopolitanism; Nation. 